\title{
The effect of culture conditions on the in-vitro adherence of methicillin-resistant Staphylococcus aureus
}

\author{
W. J. B. VAN WAMEL*, C. M. J. E. VANDENBROUCKE-GRAULS*, J. VERHOEF* \\ and A. C. FLUIT*+ \\ * Eijkman-Winkler Institute for Microbiology, Infectious Diseases and Inflammation, Utrecht University and \\ $+U$-Gene Research BV, Utrecht, The Netherlands
}

\begin{abstract}
Methicillin-resistant isolates of Staphylococcus aureus (MRSA) were divided on the basis of their epidemiologic behaviour into two subgroups, epidemic MRSA (EMRSA) and sporadic MRSA (SMRSA) strains. An existing adherence assay was modified to determine differences in adherence properties between these two groups of MRSA, and the influence of culture conditions on the adherence of SMRSA and EMRSA strains to plastic, human collagen I (HuCol I) and pharyngeal carcinoma Detroit 562 cells (D562) was determined. In-vitro parameters, such as culture medium, growth temperature and growth phase of the bacterium, influenced the adherence of MRSA strains to plastic significantly. Even more pronounced differences in adherence due to changes in growth conditions and growth phase of the bacteria were found for the adherence of MRSA strains to HuCol I. Growth phase had a significant effect on the adherence of MRSA strains to the pharyngeal carcinoma cells D562. However, the study did not find conditions which made it possible to distinguish EMRSA from SMRSA strains. These data show that extrapolation of in-vitro data concerning adherence of MRSA strains to in-vivo conditions should be treated with caution.
\end{abstract}

\section{Introduction}

Outbreaks of infection due to methicillin-resistant Staphylococcus aureus (MRSA), which may also be resistant to aminoglycosides, lincosamides, tetracyclines, quinolones and rifampicin, cause great concern in hospitals all over the world [1]. The differential ability of staphylococcal strains to spread in hospitals and cause outbreaks has been known for decades [2]. The capacity of some strains to cause outbreaks is believed to be correlated with their ability to adhere to target surfaces.

An earlier study found no correlation between the binding capacity of MRSA to extracellular matrix proteins and outbreak-related behaviour [3]. These results were unexpected, although staphylococci are well known for their capacity to show several 'faces'

Received 24 July 1997; revised version accepted 13 Nov. 1997.

Corresponding author: Dr W. J. B. Van Wamel. in response to their surroundings [4]. For instance, staphylococci grown in vivo or in vitro [5] or on solid medium or in fluid medium [6] differ in the expression of cell-associated molecules, of which several are known to be important in adherence [7]. Gene regulatory systems such as the agr and the sar loci responsible for up- and down-regulation of these cellassociated molecules might be responsible $[8,9]$.

The present study attempted to establish test conditions to make it possible to distinguish epidemic MRSA (EMRSA) strains from sporadic MRSA (SMRSA) strains. The effect of growth conditions and growth phase of the bacteria on the adherence capacity of both EMRSA and SMRSA strains to plastic, human collagen I (HuCol I) and pharynchial carcinoma Detroit 562 cells (D562) was studied. However, in existing assays bacterial adherence is dependent on the amount of bacteria added, although accurate quantification of staphylococci is impossible, which is a major drawback in a comparative study. Therefore, an adherence assay was modified to study adherence independent of the size of bacterial inoculum. 


\section{Materials and methods}

\section{Bacterial strains and culture conditions}

The MRSA strains used in this study were clinical isolates. Based on phage typing and their epidemiologic behaviour, strains were divided into two subgroups, EMRSA and SMRSA. EMRSA strains 89-227 (E01), 92-5089 (E02) and 91-10148 (E03) and SMRA strains 90-2341 (S01), 92-5090 (S02) and 91-7606 (S03) were used in this study [3]. Bacteria were stored at $-35^{\circ} \mathrm{C}$ in phosphate-buffered saline. (PBS), $\mathrm{pH} \mathrm{7.5,} \mathrm{containing}$ glycerol $12 \%$. Bacteria were grown in 12-ml tubes containing $3 \mathrm{ml}$ of Bacto Mueller Hinton Broth (Difco) or Brain Heart Broth (Difco), supplemented with $0.8 \mathrm{MBq}{ }^{3} \mathrm{H}$-adenine with a specific activity of 740 $925 \mathrm{GBq} / \mathrm{mmol}$ (Amersham, Buckinghamshire), indicated as ${ }^{3} \mathrm{H}-\mathrm{MHb},{ }^{3} \mathrm{H}-\mathrm{BHb}$ and ${ }^{3} \mathrm{H}-\mathrm{COb}$ respectively. Bacteria were cultured in ${ }^{3} \mathrm{H}-\mathrm{MHb}$ at $37^{\circ} \mathrm{C}$ and isolated at the stationary phase $(18 \mathrm{~h})$, in ${ }^{3} \mathrm{H}-\mathrm{MHb}$ at $30^{\circ} \mathrm{C}$ and isolated at the stationary phase $(18 \mathrm{~h})$, in ${ }^{3} \mathrm{H}-\mathrm{MHb}$ at $37^{\circ} \mathrm{C}$ and isolated at the mid-exponential phase $(4 \mathrm{~h})$, or in ${ }^{3} \mathrm{H}-\mathrm{BHb}$ at $37^{\circ} \mathrm{C}$ and isolated at the stationary phase $(18 \mathrm{~h}$ ). Before seeding into HLA plates (Nunc, Roskilde, Denmark), bacteria were washed three times in PBS or, in the case of adherence to D562-cells, in Hank's Balanced Salts Solution (HBSS; Gibco, Breda, The Netherlands).

\section{HLA plates}

To facilitate separation of the individual wells after incubation HLA plates (Nunc, Roskilde, Denmark) were treated with a circular drill $(6 \mathrm{~mm}$ diam.) so that the individual wells were surrounded by a moat and almost isolated (Fig. 1). The HLA plates were cleaned and sterilised. Wells of the HLA plates were used either uncoated, coated with HuCol I or covered with a monolayer of cells. HuCol I-coated HLA plates were prepared by adding $10 \mu \mathrm{l}$ of $\mathrm{HuCol} \mathrm{I} \mathrm{(Sigma)}$ $100 \mu \mathrm{g} / \mathrm{ml}$ to each well. Dehydration was prevented by placing $1 \mathrm{ml}$ of water in the moat surrounding the wells. After overnight incubation at $4^{\circ} \mathrm{C}$ the plates were washed three times with $10 \mathrm{ml}$ of PBS.

\section{Tissue culture}

To prepare HLA plates with monolayers of the pharyngeal carcinoma cells D562 (CCL 138, American Type Culture Collection, Rockville, MD, USA) the cell line was cultured in RPMI (Gibco) supplemented with

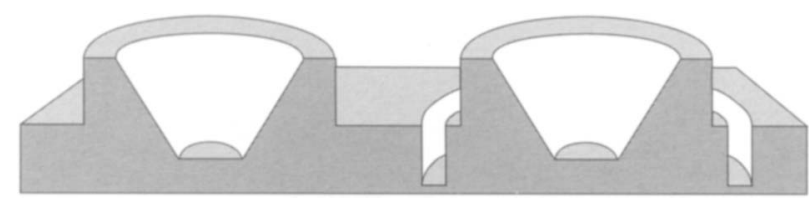

Fig. 1. Cross-section through two wells of a HLA plate. Left, untreated well; right, surrounded by a moat following treatment with a drill. fetal calf serum (Gibco) $10 \%$ (RPMI-FCS) at $37^{\circ} \mathrm{C}$ in $\mathrm{CO}_{2} 5 \%$ in air. The cells were harvested with trypsin/EDTA (Gibco) and resuspended in RPMIFCS. Ten $\mu 1$ of D562 cells $\left(2.5 \times 10^{5}\right.$ cell $\left./ \mathrm{ml}\right)$ were added to each well of an HLA plate. After incubation for $1 \mathrm{~h}$ at $37^{\circ} \mathrm{C}$ in $\mathrm{CO}_{2} 5 \%$, the cells were attached to the surface of the well. The HLA plates were placed in petri dishes and flooded with $10 \mathrm{ml}$ of RPMI-FCS. After 3-4 days a monolayer was formed, which covered the entire well. Just before use the whole HLA plate was washed three times with $10 \mathrm{ml}$ of HBSS.

\section{Adherence assay}

Labelled bacteria were washed three times with PBS or with HBSS. Bacterial suspensions were made of $c$. $2 \times 10^{9}$ bacteria $/ \mathrm{ml}$ of each strain with optical density determination at $680 \mathrm{~nm}$. Dilution series were prepared from these bacterial suspensions in the appropriate buffer. The suspensions were added to the wells of
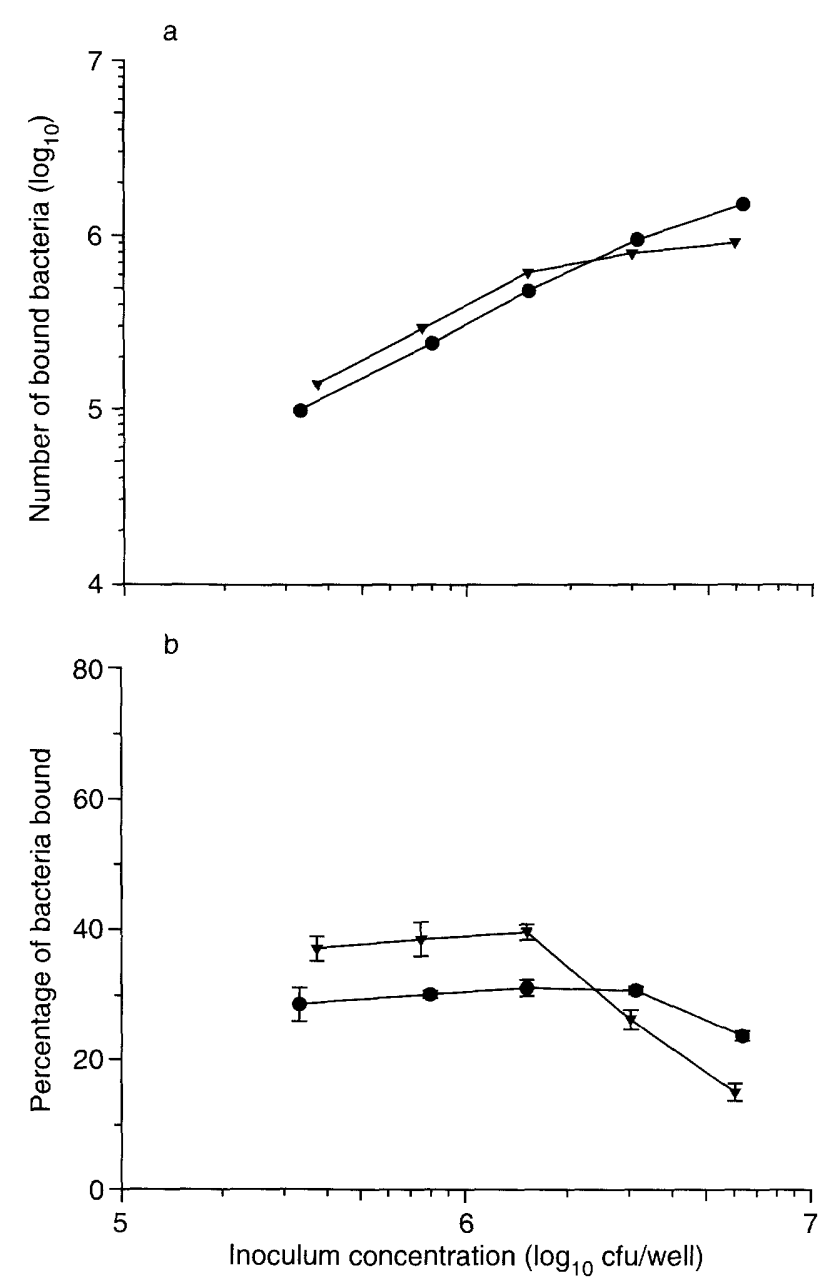

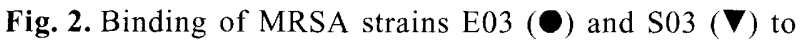
plastic. The absolute amount of bound bacteria (a) and the percentage of bound bacteria (b) were calculated and depicted (error bars are not given in (a) for the sake of clarity). 

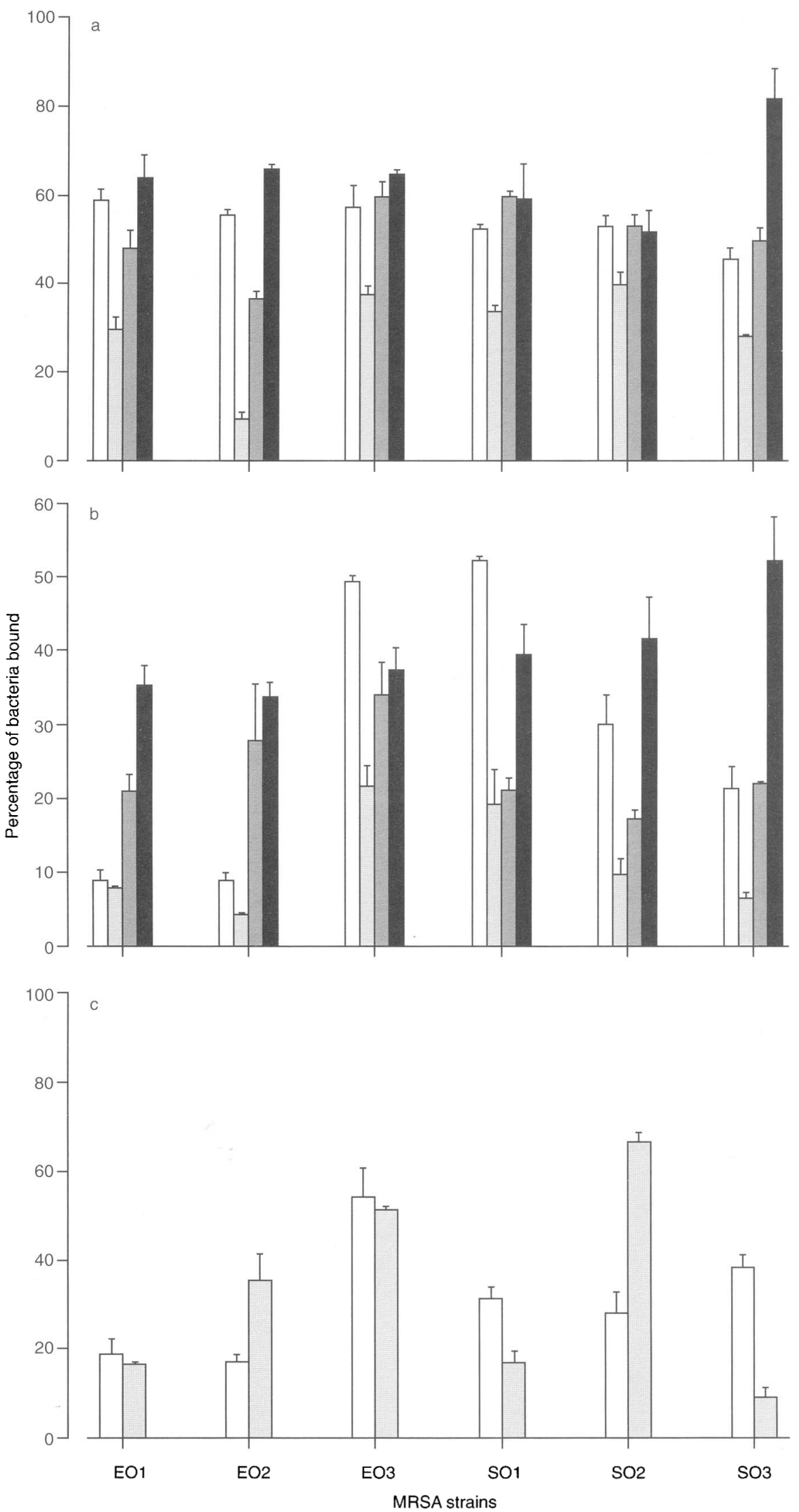

Fig. 3. The effect of growth condition and growth phase on the binding of MRSA strains E01, E02, E03, S01, S02 and $\mathrm{S} 03$. The adherence of MRSA strains E01, E02, E03, S01, S02 and S03 cultured in ${ }^{3} \mathrm{H}-\mathrm{MHb}$ at $37^{\circ} \mathrm{C}$, and isolated at the stationary phase $(\square)$; in ${ }^{3} \mathrm{H}-\mathrm{MHb}$ at $30^{\circ} \mathrm{C}$ and isolated at the stationary phase $(\square)$; in ${ }^{3} \mathrm{H}-\mathrm{MHb}$ at $37^{\circ} \mathrm{C}$ and isolated at the mid-exponential phase ( ); or in ${ }^{3} \mathrm{H}-\mathrm{BHb}$ at $37^{\circ} \mathrm{C}$ and isolated at the stationary phase (ם), to plastic (a), HuCol $\mathrm{I}$ (b) and D562 cells (c) was detected. The binding capacity of the bacteria is given as a percentage of the amount of bacteria inoculum. 
HLA plates. The plates were incubated at $37^{\circ} \mathrm{C}$ for $2 \mathrm{~h}$ (Fig. 1) to allow the bacteria to interact with the surface, or the material coated on the surface of the well. After $2 \mathrm{~h}$ the plates were rotated $180^{\circ}$ and placed upside-down, so that the free bacteria were separated from the surface of the HLA plate. After $1 \mathrm{~h}$ the plates were washed in $600 \mathrm{ml}$ of PBS by rinsing them in a vertical position three times up and down into the PBS. The individual wells were separated with the 'applecorer drill' (6 mm diam.) and the amount of ${ }^{3} \mathrm{H}$ in each well was counted. Tests were performed in triplicate and data were analysed by the $\chi^{2}$-test.

\section{Optimising the adherence assay}

To optimise the adherence assay, bacteria of strains E03 and $\mathrm{S} 03$ were grown in ${ }^{3} \mathrm{H}-\mathrm{MHb}$. At the stationary phase bacteria were washed, suspended in PBS, seeded in a range of $\left(3 \times 10^{5}\right)-\left(1.2 \times 10^{7}\right)$ bacteria/well in uncoated HLA plates, and the number of bound bacteria was determined. The relationship between the number of bacteria added and the number bound was linear when $<1 \times 10^{6}$ or $2 \times 10^{6}$ bacteria/well of strains S03 or E03, respectively, were added (Fig. 2a). Therefore, the percentage binding was independent of the amount of added bacteria over this range (Fig. 2b). Similar tests were performed with all six MRSA strains and the adherence of the bacteria to plastic, HuCol I and D562 cells was measured. In all cases the percentage of bound bacteria was independent of the amount of added bacteria, if $<1 \times 10^{6}$ bacteria/well were used (data not shown).

\section{Effect of culture conditions on adherence of MRSA strains}

The effect of growth temperature and growth phase of the adherence of six MRSA strains (E01, E02, E03, $\mathrm{S} 01, \mathrm{~S} 02$ and S03) to plastic and $\mathrm{HuCol} \mathrm{I}$ was investigated. Stationary phase bacteria cultured in ${ }^{3} \mathrm{H}$ $\mathrm{MHb}$ at $37^{\circ} \mathrm{C}$ and at $30^{\circ} \mathrm{C}$, mid-exponential phase bacteria cultured in ${ }^{3} \mathrm{H}-\mathrm{MHb}$ at $37^{\circ} \mathrm{C}$, or stationary phase bacteria cultured in ${ }^{3} \mathrm{H}-\mathrm{BHb}$ at $37^{\circ} \mathrm{C}$ were washed in PBS. Bacteria were seeded at concentrations of $3 \times 10^{5}$ and $6 \times 10^{5}$ bacteria/well in HLA plates, either uncoated or coated with $\mathrm{HuCol} I$, and the number of bacteria bound was determined. All tests were performed in triplicate.

The effect of growth phase on the adherence of the six MRSA strains to monolayers of D562 cells was also studied. Mid-exponential phase and stationary phase bacteria cultured in ${ }^{3} \mathrm{H}-\mathrm{MHb}$ were washed in HBSS. Bacteria were seeded in HLA plates coated with D562 cells at a concentration of $3 \times 10^{5}$ or $6 \times 10^{5}$ bacteria/well and the number of bound bacteria was determined. All tests were performed in triplicate.

\section{Results}

Effect of growth temperature, growth phase and growth medium on the adherence of six MRSA strains to plastic

Stationary phase bacteria from all MRSA strains cultured in ${ }^{3} \mathrm{H}-\mathrm{MHb}$ at $30^{\circ} \mathrm{C}$ showed a significantly reduced adherence to plastic $(p<0.025)$ compared with bacteria grown at $37^{\circ} \mathrm{C}$ (Fig. 3a). Bacteria of strains E01 and E02 grown to mid-exponential phase showed a significant reduction of binding to plastic $(p<0.025)$ compared with those grown to stationary phase. Bacteria of MRSA strains S01 and S03 grown to mid-exponential phase showed a slight increase of binding to plastic over bacteria grown to stationary phase. No growth phase-dependent adherence to plastic was found for strains E03 and S02. When binding to plastic of stationary phase bacteria grown in ${ }^{3} \mathrm{H}-\mathrm{BHb}$ was compared with that of bacteria grown in ${ }^{3} \mathrm{H}-\mathrm{MHb}$ at $37^{\circ} \mathrm{C}$, a significant increase of binding to plastic $(p<0.025)$ was found only for strains E02 and S03. In all experiments, the percentage of bound bacteria found for the two assay concentrations differed by $<10 \%$, indicating that under these circumstances the test was independent of the amount of bacteria added.

Adherence to plastic did not distinguish EMRSA strains from SMRSA strains under any of the conditions tested.

\section{Effect of growth phase and growth medium on the adherence of six MRSA strains to HuCol I}

The adherence to HuCol I of stationary phase bacteria of all MRSA strains grown in ${ }^{3} \mathrm{H}-\mathrm{MHb}$ at $30^{\circ} \mathrm{C}$ was significantly lower $(p<0.025)$ than for bacteria grown at $37^{\circ} \mathrm{C}$, except for strain E01, which showed no growth temperature-dependent adherence to $\mathrm{HuCol} \mathrm{I}$. Adherence to HuCol I was growth phase-dependent for all strains except for strain S03. Bacteria of strains E01 and E02 grown to mid-exponential phase in ${ }^{3} \mathrm{H}-\mathrm{MHb}$ at $37^{\circ} \mathrm{C}$ showed a significant increase of adherence to HuCol I $(\mathrm{p}<0.025)$ compared with bacteria grown to stationary phase. For strains E03, S01 and S02, bacteria grown to mid-exponential phase adhered significantly less well to HuCol I $(\mathrm{p}<0.025)$ than bacteria grown to stationary phase. The adherence of stationary phase bacteria of all strains to $\mathrm{HuCol}$ I was dependent on the culture medium used. Bacteria of MRSA strains E01, E02, S02 and S03 grown in ${ }^{3} \mathrm{H}-\mathrm{BHb}$ showed a significant increase of binding to $\mathrm{HuCol} \mathrm{I}(\mathrm{p}<0.025)$ and bacteria of strains E03 and S01 showed a significant decrease in binding to $\mathrm{HuCol} \mathrm{I}(\mathrm{p}<0.025)$ in comparison with bacteria grown in ${ }^{3} \mathrm{H}-\mathrm{MHB}$ (Fig. 3b). Like the results of binding to plastic, the percentage of bacteria bound to $\mathrm{HuCol} \mathrm{I}$, at the two concentrations assayed, differed by $<10 \%$. This indicated that under these circumstances the test was independent of the amount of bacteria added. 
In none of the conditions tested was it possible to distinguish EMRSA from SMRSA strains on the basis of adherence to HuCol I.

\section{Effect of growth phase on the adherence of six MRSA strains to D562 cells}

Adherence of bacteria of MRSA strains E02 and S02 grown to mid-exponential phase was significantly higher $(p<0.025)$ than that of bacteria grown to stationary phase. However, the adherence of bacteria in exponential phase of MRSA strains S01 and S03 was significantly lower $(p<0.025)$ than that of stationary phase bacteria. The adherence of MRSA strains E01 and E03 to D562 cells was independent of the growth phase (Fig. 3c). Once more, the percentage of bound bacteria found in the adherence of MRSA strains to D562 cells, at the concentrations assayed, differed by $<10 \%$. This indicated that under these circumstances the test was independent of the amount of bacteria added.

In none of the conditions tested was adherence to D562 cells able to distinguish EMRSA from SMRSA strains.

\section{Discussion}

Spread of MRSA is an increasing problem in modern health care. The reason why some MRSA cause outbreaks and others do not is unknown. Knowledge about the mechanisms that are significant in MRSA strains that cause outbreaks may provide the possibility to interfere with this spread. Differences in resistance to antibiotics, dehydration [10] or other survival features may play a role in the ability to cause an outbreak. As adherence is believed to be the first step in colonisation, the ability to cause an outbreak is often explained by an organism's capacity to adhere to target surfaces. In an earlier study, outbreak-related and nonoutbreak-related MRSA strains were tested for their ability to bind to extracellular matrix proteins, but no correlation was found between the binding of these proteins by MRSA strains and their ability to cause an outbreak [3]. As staphylococci are known to express different surface structures depending on growth conditions, the present study investigated the influence of culture conditions on in-vitro adherence of both EMRSA and SMRSA strains to different surfaces. Information about these factors might lead to the definition of assay conditions that allow the discrimination of EMRSA from SMRSA strains in vitro.

In the comparitive adherence assays needed for these kind of studies, an important source of variation is the fact that, in most of the methods, adherence is dependent on the amount of bacteria added. To overcome these problems an adherence assay was modified, to obtain adherence independent of the amount of bacterial inoculum. This method made it possible to investigate the influence of culture conditions on the adherence of both EMRSA and SMRSA strains to plastic, human collagen I and the pharyngeal carcinoma cell line D562 in a reproducible manner.

In general, culture conditions influenced adherence to plastic, although some exceptions were observed. Differences in adherence due to changes in culture conditions were even more pronounced when $\mathrm{HuCol} \mathrm{I}$ coated plates were used, or when adherence to D562 cells was determined. All this is in agreement with several reports showing that different culture conditions result in different expression of cell-associated proteins in $S$. aureus $[5,6,11]$. However, the study was not able to establish conditions that allowed EMRSA strains to be distinguished from SMRSA strains.

As most parameters tested in-vitro clearly affected the adherence of MRSA strains, and little is known about the in-vivo conditions before and during adherence, these data indicate that extrapolation of in-vitro data concerning adherence of MRSA strains to the in-vivo situation should be treated with caution.

We thank R. H. J. Mansvelt Beck for technical assistance. This work was supported by grant 0028-21090 from the Dutch Prevention Fund.

\section{References}

1. Brumfitt W, Hamilton-Miller J. Methicillin-resistant Staphylococcus aureus. N Engl J Med 1989; 320: 1188-1196.

2. Williams DN, Peterson PK, Verhoef J, Laverdiere M, Sabath LD. Endocarditis caused by coagulase-negative staphylococci Infection 1979; 7: 5-9.

3. Van Wamel WJB, Fluit AC, Wadström T, van Dijk H, Verhoef $\mathrm{J}$, Vandenbroucke-Grauls CMJE. Phenotypic characterization of epidemic versus sporadic strains of methicillin-resistant Staphylococcus aureus. J Clin Microbiol 1995; 33: 1769-1774.

4. Stock JB, Ninfa AJ, Stock AM. Protein phosphorylation and regulation of adaptive responses in bacteria. Microbiol Rev 1989; 53: 450-490.

5. Watson DL. Virulence of Staphylococcus aureus grown in vitro or in vivo. Res Vet Sci 1982; 32: 311-315.

6. Cheung AL, Fischetti VA. Variation in the expression of cell wall proteins of Staphylococcus aureus grown on solid and liquid media. Infect Immun 1988; 56: 1061-1065.

7. Patti JM, Allen BL, McGavin MJ, Hook M. MSCRAMMmediated adherence of microorganisms to host tissues. Annu Rev Microbiol 1994; 48: 585-617.

8. Cheung AL, Kooney JM, Butler CA, Projan SJ, Fischetti VA Regulation of exoprotein expression in Staphylococcus aureus by a locus (sar) distinct from agr. Proc Natl Acad Sci USA 1992; 89: 6462-6466.

9. Kornblum J, Kreiswirth BN, Projan SJ, Ross H, Novick RP Agr: a polycistronic locus regulating exoprotein synthesis in Staphylococcus aureus. In: Novick RP (eds) Molecular biology of the staphylococci. New York, VCH. 1990: 373-402.

10. Beard-Pegler MA, Stubbs E, Vickery AM. Observations on the resistance to drying of staphylococcal strains. J Med Microbiol 1988; 26: $251-255$.

11. Gemmell CG. Antibiotics and the expression of staphylococcal virulence. J Antimicrob Chemother 1995; 36: 283-291. 